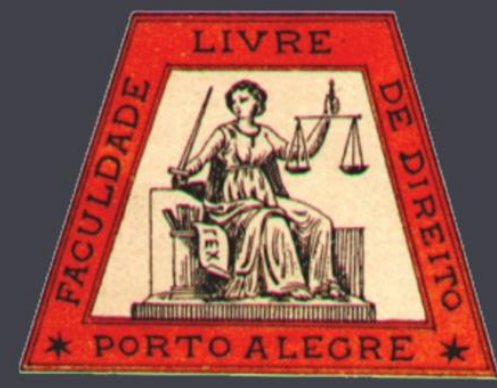

A precariedade está por toda parte: um estudo das origens e consequências da precariedade do trabalho no mundo globalizado

Precariousness is everywhere: a study of the origins and consequences of the precariousness of work in the globalized world

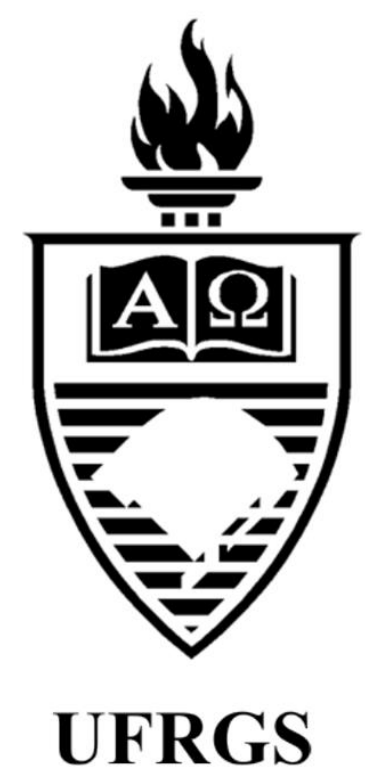

Rafaela Ribeiro Zauli Lessa

Universidade Federal de Minas Gerais 


\title{
A precariedade está por toda parte: um estudo das origens e consequências da precariedade do trabalho no mundo globalizado
}

\author{
Precariousness is everywhere: a study of the origins and consequences of the precariousness of work \\ in the globalized world
}

\author{
Rafaela Ribeiro Zauli Lessa*
}

\begin{abstract}
REFERÊNCIA
LESSA, Rafaela Ribeiro Zauli. A precariedade está por toda parte: um estudo das origens e consequências da precariedade do trabalho no mundo globalizado. Revista da Faculdade de Direito da UFRGS, Porto Alegre, n. 34, p. 203-217, ago. 2016.
\end{abstract}

\section{RESUMO}

O processo globalizante intensificado nos anos 1990 pela industrialização e pela modernização generalizadas, aliado a fatores como o fim do Estado do Bem-Estar Social, o surgimento das transnacionais e a eclosão do Pós-Fordismo, abalou profundamente o primado do trabalho e emprego, resultando no fenômeno conhecido como "desemprego estrutural", levando à precarização do emprego. As transnacionais, empresas "flexíveis", exploram a insegurança criada por elas mesmas. Ao colocar o trabalhador permanentemente em risco de perder seu trabalho, ela baixa seus custos sem oposição, promovendo o fenômeno da "flexploração". Ao mesmo tempo, o novo modelo produtivo Pós-Fordista contribuiu para instaurar uma outra marginalização social, em que o trabalhador precarizado não se vê como um sujeito coletivo capaz de exigir direitos e dignidade e o trabalhador das empresas principais se vê dependente e incapaz de sustentar seus pleitos trabalhistas.

\section{PALAVRAS-CHAVE}

Direito do trabalho. Precariedade. Marginalização. PósFordismo.

\begin{abstract}
The globalizing process intensified in the 1990s by industrialization and widespread modernization, combined with factors such as the end of the Social Welfare State, the emergence of transnational companies and the outbreak of post-Fordism, deeply affected the primacy of work and employment, resulting in the phenomenon known as "structural unemployment", leading to precarious employment. Transnational, "flexible", companies exploit the uncertainty created by themselves. By placing the worker permanently at risk of losing her job, they lower their costs without opposition, promoting the phenomenon of "flexploitation". At the same time, the new post-Fordist production model helped to establish another social marginalization, where the precarious worker does not see herself as a collective subject able to demand rights and dignity and the worker of the major companies sees herself dependent and unable to sustain her labor claims.
\end{abstract}

\section{KEYWORDS}

Labor law. Precariousness. Marginalization. PostFordism.

\section{SUMÁRIO}

Introdução. 1. O conceito de precariedade. 2. O agravamento da precariedade pelo fenômeno da globalização. 3. A transição entre o Fordismo e o Pós-Fordismo e a manutenção da precariedade. 4. Consequências da transição: a nova marginalização. Conclusão. Referências.

\footnotetext{
* Mestranda em Direito (Universidade Federal de Minas Gerais - UFMG). Especialista em Direito de Empresa (Pontifícia Universidade Católica de Minas Gerais, 2014). Graduada em Direito (Universidade Federal de Minas Gerais - UFMG, 2013). Advogada.
} 


\section{INTRODUÇÃO}

Com a intensificação do processo globalizante nos anos 1990, observou-se a industrialização e a modernização generalizadas, decorrentes do fim das barreiras para a transferência de tecnologias e técnicas de produção, o que acabou por dar origem a uma nova divisão do trabalho. Países emergentes passaram a sediar grandes transnacionais atraídas pela abundante oferta de mão de obra, pela permissibilidade das precárias condições de trabalho, pelo potencial consumidor e pelo oferecimento de subsídios estatais.

Fatores como a terceira revolução tecnológica, a nova divisão internacional do trabalho, a acentuação da concorrência capitalista internacional, e a transição entre o antigo modelo fordista para o Pós-Fordismo impactaram o antigo primado do trabalho e emprego, levando à paulatina desvalorização da força de trabalho e degradação dos trabalhadores.

Nesse contexto, o presente trabalho busca evidenciar qual o papel da globalização para o adensamento da precariedade nas relações de trabalho, qual a influência da alteração do modelo de produção Pós-Fordista para a manutenção das situações degradantes das forças de trabalho em todo o mundo e, finalmente, quais as consequências dessa conjuntura econômica para o mundo do trabalho, que passa, agora, a contar com novas margens.

Como proposta de análise dessas questões centrais de investigação, além de compor-se de introdução e conclusão, o presente artigo dividese em quatro grandes partes. Primeiramente, descreve-se o fenômeno da precariedade no trabalho, esclarecendo seu conceito e efeitos. A segunda parte atém-se ao estudo da globalização como fator de agravamento da precariedade, uma vez que alimentou as chamadas empresas "flexíveis", livres das amarras territoriais. No terceiro item, avalia-se a transição entre os modelos produtivos do Fordismo e do PósFordismo e como essa trajetória representou um retrocesso para as relações de trabalho. Por fim, no último tópico, evidenciam-se as consequências do novo modelo econômico produtivo para a situação de sujeição dos trabalhadores e, principalmente, para a maximização da marginalização trabalhista.

\section{O CONCEITO DE PRECARIEDADE}

A emergência de um novo modelo de organização do trabalho e de regulação social baseado na flexibilidade da produção e das relações de trabalho, cujo despertar será descrito nos itens seguintes, foi o que culminou na precarização do trabalho. Com o fím do Estado do Bem-Estar Social e com a intensificação do processo globalizante, a competitividade e a insegurança no trabalho mostraram-se incompatíveis com o pleno emprego e diversas garantias sociais. A nova formatação do capitalismo pós-industrial ou pós-fordista trouxe consigo a desestabilização da relação de trabalho padrão, compreendida como um dos pilares do florescimento do Direito do Trabalho moderno. ${ }^{1}$

Conforme explica Robert Castel, o avanço das políticas neoliberais, a reestruturação produtiva, a crise da sociedade salarial e o fim das barreiras territoriais resultaram em um processo profundo de desarticulação da classe trabalhadora, de suas formas de organização coletiva e de seu sistema de direitos e proteções, institucionalizando-se um novo modelo de regulação, o "precariado", alicerçado na ruptura do emprego estável ${ }^{2}$, por tempo indeterminado e

${ }^{1}$ FUDGE, Judy; TUCKER, Eric; VOSKO, Leah F. The legal concept of employment: marginalizing workers. Report for the Law Comission of Canada. Set, 2002. p. 120.

${ }^{2}$ Para Robert Castel, a sociedade hoje é marcada por zonas de coesão social: integrados - trabalhadores estáveis assalariados e abarcados pelas normas de proteção social; vulneráveis - trabalhadores em situação de risco; e 
integral, e na ascensão das formas atípicas de emprego $^{3}$, muitas vezes coincidentes com o trabalho informal.

A flexibilização e a informalização da força de trabalho foram os caminhos utilizados pelo capital para "arquitetar e ampliar a intensificação, a exploração e a precarização do trabalho em escala global". ${ }^{4}$

A estratégia de diminuição dos custos do trabalho justificada pelo argumento de que a medida estimula a criação de novos postos de trabalho é um recurso adotado pelas empresas, grandes grupos econômicos e, até mesmo, pelo Estado. Ao contrário do que prega o empresariado, este tipo de política apenas tem contribuído ativamente para a criação de um número cada vez maior de empregos de estatuto precário. A estrutura alicerçada nessa linha de atuação significa não apenas que os novos empregos criados são precários, mas também que se verifica uma tendência de precarização dos empregos já existentes. ${ }^{5}$

A precariedade no trabalho decorre, sobretudo, da concorrência e da insegurança generalizadas frutos das altas taxas de desemprego e subemprego. Os desempregados e os trabalhadores sem estabilidade não são passíveis de mobilização, por serem incapazes de se projetarem para o futuro. ${ }^{6}$ Por essa razão, tal contexto social permite o alastrar de situações de

desfiliados - os que estão fora da sociedade salarial. (CASTEL, Robert. Metamorfoses da questão social. Petrópolis: Vozes, 1998. p. 33-34)

${ }^{3}$ CASTEL, Robert. La montée des incertitudes. Travail, protections, statut de l'individu. Paris: Éditions du Seuil, 2009. p. 54.

${ }^{4}$ ANTUNES, Ricardo. Os modos de ser da informalidade: rumo a uma nova era da precarização estrutural do trabalho? Serviço Social e Sociedade, São Paulo, n. 107, julho/setembro, 2011. p.4.

5 ALVES, G. Dimensões da Reestruturação Produtiva: Ensaios de Sociologia do Trabalho. 2. ed. Londrina: Praxis, 2007. p. 245.

${ }^{6}$ BOURDIEU, Pierre. A precariedade está hoje por toda parte. In: BORDIEU, Pierre. Contrafogos: táticas para enfrentar a invasão neoliberal. Rio de Janeiro: Jorge Zahar, 1998. p. 73. precariedade surgidas dentro do grupo dos "trabalhadores periféricos" aos antigos trabalhadores estáveis, atingidos pela insegurança subjetiva generalizada. Trata-se, nas palavras de Robert Castel, da "desestabilização dos estáveis". 7

A precariedade consiste em um modo de dominação fundado na instituição generalizada e permanente de insegurança, com o objetivo de obrigar os trabalhadores à aceitação da exploração. ${ }^{8}$ Em síntese, atua diretamente sobre aqueles aos quais afeta (e que ela impede, efetivamente, de serem mobilizados) e indiretamente sobre todos os outros, pelo temor que ela suscita, criando ambiente propício à instauração de estratégias de precarização, como a famosa "flexibilidade". 9

A empresa que explora a flexibilidade aproveita-se de uma situação de insegurança que ela contribui para reforçar: ela baixa os custos com garantias sociais, mas também torna possível essa baixa, pondo o trabalhador em risco permanente de perder o seu trabalho. Todo o universo da produção, material e cultural, pública e privada, é assim arrebatado num vasto processo de precarização, aprimorado com a desterritorialização da empresa. ${ }^{10}$

${ }^{7}$ CASTEL, Robert. Les Métamorphoses de la question sociale. Paris: Gallimard, 1995.

${ }^{8}$ BOURDIEU, Pierre. A precariedade está hoje por toda parte. In: BORDIEU, Pierre. Contrafogos: táticas para enfrentar a invasão neoliberal. Rio de Janeiro: Jorge Zahar, 1998. p. 75.

${ }^{9}$ Robert Castel identifica dois tipos de flexibilidade: uma "flexibilidade interna" às empresas, que impõe adaptabilidade da mão de obra a situações novas e que expulsa dos melhores empregos os que não se enquadram às novas regras do jogo; e uma "flexibilidade externa", articulada à primeira, que é aquela que conduz as grandes empresas a subcontratar de terceiros grande parte das tarefas da empresa, mas, em geral, sob condições mais precárias, menos protegidas e com menos direitos (CASTEL, Robert. As transformações da questão social. In: CASTEL, R; WANDERLEY L. E. W.; BELFIOREWANDERLEY, M. Desigualdade e a questão social. São Paulo: EDUC, 2004. p. 247-248).

${ }^{10}$ Ibidem, p. 74. 
As novas figuras do mercado de trabalho mostram-se como formas ocultas de trabalho assalariado, subordinado, precarizado, não garantido, de trabalho autônomo de última geração, que decorrem da eliminação do ciclo produtivo. Na verdade, trata-se de uma nova marginalização social, em que o trabalhador precarizado e difuso tem dificuldade de perceber-se como sujeito coletivo e capaz de exigir direitos e dignidade, alimentando a permanência da situação de degradação do trabalho. ${ }^{11}$

A precariedade corresponde, como explica Castel, ao alargamento da zona intermediária entre o emprego estável e o desemprego, e reforça a precariedade na periferia do mercado de trabalho, a "zona híbrida da vida social entre trabalho e não trabalho, segurança e assistência, integração e desfiliação", onde faltam as condições para o indivíduo construir a sua independência econômica e social e enxergar-se como sujeito coletivo de direitos. ${ }^{12}$

\section{O AGRAVAMENTO DA PRECARIEDADE PELO FENÔMENO DA GLOBALIZAÇÃO}

A Nova Ordem Mundial, desenvolvida na década de 80, no pós-Guerra Fria, representou, do ponto de vista econômico e tecnológico, o reconhecimento da hegemonia capitalista e o florescer da multipolaridade. $\mathrm{O}$ antigo contexto bipolar foi substituído pelo surgimento de economias emergentes e novos e potentes blocos econômicos. Seu principal efeito foi o despertar do processo de globalização e a consequente integração internacional.

No primeiro momento da nascente ordem, a supremacia capitalista se viu aliada ao Estado

\footnotetext{
${ }^{11}$ VASAPOLLO, Luciano. A precariedade como elemento estratégico determinante do capital. Pesquisa \& Debate, São Paulo, v. 16, n. 2(28), p. 368-386, 2005. p. 385.

12 CASTEL, Robert. El ascenso de las incertidumbres. Trabajo, protecciones, estatuto del individuo. Buenos Aires: Fondo de Cultura Económica, 2010. p. 29.
}

do Bem-Estar Social, estrutura política que eclodiu para a mitigação dos impactos negativos causados pelas guerras anteriores. A valorização do homem e o assistencialismo estatal levaram ao primado do trabalho e do emprego, pilar que se sedimentou na aludida forma de gestão pública, em boa parte do século XX no Ocidente, acabando por incrustar-se, também, no Direito. A ideia de exaltação do trabalho disseminou-se, inclusive, para os países que não passaram pela experiência do Welfare State, incorporando-se à cultura jurídica de tais nações. ${ }^{13}$

No decorrer do processo globalizante nos anos 90, observou-se a industrialização e a modernização generalizadas, possíveis em razão do fim das barreiras para a transferência de tecnologias e técnicas de produção, instaurandose mundialmente uma nova divisão do trabalho. Países emergentes sediavam, então, grandes transnacionais atraídas pela abundante oferta de mão de obra, pela permissibilidade das precárias condições de trabalho, pelo potencial consumidor e pelo oferecimento de subsídios estatais.

Essa conjuntura capitalista juntamente com o fim gradual do Estado do Bem-Estar Social alteraram as bases do mundo do trabalho, resultando no fenômeno conhecido como "desemprego estrutural". ${ }^{14}$ A globalização e o desenvolvimento do ultraliberalismo ${ }^{15}$, a terceira

${ }^{13}$ DELGADO, Maurício Godinho. Capitalismo, trabalho e emprego: entre o paradigma da destruição e os caminhos de reconstrução. São Paulo: LTr, 2006. p. 11.

$14 \mathrm{O}$ desemprego estrutural é o fenômeno decorrente do direcionamento do capital produtivo para a especulação na esfera financeira e da automação sem limites da produção, constituindo novos modelos de produção que contratam pouco e extinguem postos de trabalho, aumentando a carga sobre os empregados que permanecem na empresa e levando à priorização da terceirização e dos contratos temporários (GONÇALVES, Antônio Fabrício de Matos. Flexibilização trabalhista. Belo Horizonte: Mandamentos Editora, 2004. p. 112).

15 " [...] a ideia de ultraliberalismo revela-nos a radicalidade - no sentido de implementação de uma agenda bem determinada e em razão de seu modus operandi - com que os liberais do século XX atuaram visando a obtenção da 
revolução tecnológica, o processo de reestruturação empresarial e o surgimento das transnacionais, a acentuação da concorrência capitalista internacional, a formação da matriz intelectual apologética quanto ao suposto fim do emprego e, finalmente, as modificações jurídicas implementadas na configuração institucional do mercado de trabalho, impactaram o antigo primado do trabalho e emprego, levando à paulatina desvalorização da força de trabalho e degradação dos trabalhadores ${ }^{16}$, tornando $\mathrm{o}$ trabalho cada vez mais precário. ${ }^{17}$

Ao facilitar a mobilidade do capital e a migração de empresas para os países com salários mais baixos, nos quais o custo do trabalho é reduzido, a globalização favoreceu a extensão da concorrência entre os trabalhadores em escala mundial. A empresa nacional, que se preocupava exclusivamente com a concorrência de seu próprio território, cedeu lugar às multinacionais, cuja atuação acirra a concorrência entre os trabalhadores não somente de um único país, mas de todo o mundo, na medida em que é "flexível" e sua localização se define de acordo com a aceitação (ou não) de condições deploráveis de trabalho. ${ }^{18}$

A empresa "flexível" explora a insegurança reforçada por ela própria. Ao colocar o trabalhador permanentemente em risco de perder seu trabalho, ela baixa seus custos sem oposição, promovendo o fenômeno da "flexploração", entendido esse como a gestão racional da

hegemonia" (FONSECA, Francisco. $O$ Consenso Forjado - a grande imprensa e a formação da agenda ultraliberal no Brasil. São Paulo: HUCITEC, 2005. p. 28, 49).

${ }^{16}$ DELGADO, Maurício Godinho. Capitalismo, Trabalho e emprego: entre o paradigma da destruição e os caminhos de reconstrução. São Paulo: LTr, 2006. p. 34-35.

17 LESSA, R. R. Z.; REIS, D. M.. Submissão das corporações a sanções internacionais e meios não estatais de reparação: Possíveis soluções à ineficácia social do Direito ao Trabalho Decente. Anuário Brasileiro de Direito Internacional, v. 2, p. 89-113, 2015.

${ }^{18}$ BOURDIEU, Pierre. A precariedade está hoje por toda parte. In: BORDIEU, Pierre. Contrafogos: táticas para enfrentar a invasão neoliberal. Rio de Janeiro: Jorge Zahar, 1998. p. 74. insegurança pelas transnacionais que, por meio da manipulação do espaço da produção, exalta a concorrência entre os trabalhadores dos países com conquistas sociais mais importantes e resistências sindicais mais organizadas e os trabalhadores dos países menos avançados socialmente, quebrando as resistências e obtendo obediência e submissão. Em outras palavras, instaura-se a precariedade. ${ }^{19}$

A globalização implicou na redução de garantias para os trabalhadores dos países desenvolvidos, acuados pela ameaça crescente do desemprego e da transferência física dos meios de produção, prática conhecida como dumping social, gerando vantagens econômicas às empresas que exploram a mão de obra nos países em desenvolvimento. ${ }^{20}$

A realidade mundial controlada pelas transnacionais apresenta um panorama de extrema degradação do mundo do trabalho. Exemplos como os noticiados em 2012, pela ONG Human Rights Watch sobre o trabalho infantil de mulheres na Guiné ${ }^{21}$ e no Marrocos ${ }^{22}$, as quais chegam a trabalhar de doze a dezoito horas por dia, durante sete dias por semana, evidenciam a situação precária dos trabalhadores no contexto mundial.

De acordo com recente relatório da $\mathrm{OIT}^{23}$, o número de empregados no mundo cresce desde

\footnotetext{
${ }^{19}$ Ibidem.

${ }^{20}$ BARRAL, Welber. Dumping e comércio internacional: a regulamentação antidumping após a rodada Uruguai. Rio de Janeiro: Forense, 2000. p. 14.

${ }^{21}$ HUMAN RIGHTS WATCH. Bottom of the Ladder: Exploitation and Abuse of Girl Domestic Workers in Guinea. Nova York, 2007. Disponível em: <http://www.hrw.org/sites/default/files/reports/guinea0607 webwcover.pdf $>$. Acesso em: 25 set. 2013.

${ }^{22}$ HUMAN RIGHTS WATCH. Lonely Servitude: Child Domestic Labor in Morocco. Nova York, 2012. Disponível em:

$<$ http://www.hrw.org/sites/default/files/reports/morocco10 12ForUpload_2.pdf $>$. Acesso em: 25 set. 2013.

${ }^{23}$ OIT. World of Work Report 2013 - Repairing the economic and social fabric. Disponível em: <http://www.oit.org.br/sites/default/files/topic/gender/doc/ relatoriocompletowow13_1037.pdf>. Acesso em: 03 out. 2013.
} 
1995, tendo ultrapassado, em 2013, 200 milhões de pessoas. Por outro lado, mais da metade de todos os trabalhadores ocupados no mundo vive atualmente com menos de US\$ 2 por dia, em uma situação de pobreza. O índice de trabalho infantil mundial também se mostra preocupante, sendo hoje de 168 milhões de crianças.

Todo o arcabouço protetivo criado pelos organismos internacionais não tem se mostrado suficiente para a limitação da mencionada flexploração. Isso porque, o plano normativo estabelecido sobre a temática dos Direitos Humanos e, em especial os direitos laborais, apresenta-se, na atualidade, inaplicável a atores não-estatais e, portanto, às grandes corporações.

A capacidade de atuação das grandes companhias parece não ter limites. As leis nacionais de direitos humanos são designadas para operar apenas intraterritorialmente, fazendo com que as operações extraterritoriais dessas corporações - a própria característica que as define - não sejam reguladas nem pelas leis internacionais, nem pelas leis domésticas, no que tange ao impacto dessas companhias aos Direitos Humanos. Além disso, são comuns os eventos em que a repressão a violações a Direitos Humanos com base na legislação dos Estados hospedeiros é entrevada pela influência das corporações sobre governantes locais, principalmente nos casos em que a atividade das primeiras se mostre vital ao desenvolvimento de regiões mais pobres. ${ }^{24}$

Como se não bastasse, as regulações internacionais que se propõem a tratar da questão apresentam-se como mera implicação de standards e práticas atualmente existentes para Estados e empresas e não, portanto, como inovação legal. ${ }^{25}$ De forma geral, afere-se um

\footnotetext{
${ }^{24}$ KINLEY, D.; TADAKI, J. From talk to walk: The emergence of human rights responsibilities for corporations at international law. Virginia Journal of International Law, v. 44, n. 4, p. 931-1023.

25 MARTINS ZANITELLI, Leandro. Corporações e Direitos humanos: O Debate entre Voluntaristas e
}

caráter não-obrigatório, não-vinculável e voluntarista dos instrumentos de soft law atinentes à responsabilidade social corporativa, que justificam a constatada ineficácia dos Direitos Humanos, em especial os de proteção ao trabalho, na atuação e nas atividades das grandes corporações. $^{26}$

Prova do exposto são os recorrentes casos de violações aos direitos humanos do trabalho por transnacionais noticiados reiteradamente, dentre os quais, expõem-se alguns exemplos mais recentes.

O notável caso de Rosarno, na Calábria, Itália, foi revelado por uma pesquisa realizada pela "The Ecologist" e, posteriormente filmado pelo "The Independent". Trata-se de uma colheita de laranjas para a produção de um refrigerante de marca conhecida pertencente à Coca-Cola, que era feita em condições de escravidão pelas mãos de imigrantes da África, muitas vezes depois de terem atingido a costa italiana após uma triste travessia que seria a única esperança de sobrevivência para aquelas pessoas. $^{27}$

Em 2010, a multinacional do tabaco Philip Morris reconheceu a presença, em suas plantações, de pelo menos 72 crianças de 10 anos de idade, envolvidas na colheita do tabaco e em risco de sofrerem intoxicação por nicotina. A empresa, ainda, forçava trabalhadores imigrantes ao trabalho escravo, sequestrando seus

Obrigacionistas e o Efeito Solapador das Sanções. Sur Revista Internacional de Direitos humanos, v. 8, n. 15, dez. 2011. Semestral. Disponível em: <http://www.surjournal.org/conteudos/pdf/15/02.pdf >. Acesso em: 11 fev. 2014.

26 LESSA, R. R. Z.; REIS, D. M.. Submissão das corporações a sanções internacionais e meios não estatais de reparação: Possíveis soluções à ineficácia social do Direito ao Trabalho Decente. Anuário Brasileiro de Direito Internacional, v. 2, p. 89-113, 2015.

${ }^{27}$ MILMO, Cahal. The hard labour behind soft drinks. The Independent. Reino Unido, 24 fev. 2012. Disponível em: <http://www.independent.co.uk/life-style/food-anddrink/features/the-hard-labour-behind-soft-drinks7440046.html>. Acesso em: 13 jul. 2014. 
documentos e forçando-os ao trabalho contínuo, sem qualquer compensação. ${ }^{28}$

Outra empresa envolvida com violações é a Hershey's que sofreu acusações de escravidão feitas pela "Labor Rights Forum". Embora a empresa tenha firmado um acordo contra o trabalho escravo infantil há dez anos, milhares de crianças ainda colhem cacau na África para a multinacional do chocolate..$^{29}$

\section{A TRANSIÇÃO ENTRE O FORDISMO E O PÓS-FORDISMO E A MANUTENÇÃO DA PRECARIEDADE}

O modo de produção fordista, que teve seu apogeu na segunda década do século XX e pautou-se principalmente nas premissas tayloristas, alicerçava-se no trabalho parcelado em longas cadeias de montagem concebidas para a produção em grande série de produtos padronizados. A organização do trabalho destinava-se a retirar do operário o máximo de rendimento, mantendo-o em um sistema de obrigações que the retirava qualquer margem de iniciativa, dado o seu objetivo único de produção em massa. ${ }^{30}$

Os trabalhadores não forneciam totalmente sua capacidade de trabalho. A alta administração das empresas buscava assegurar o controle pleno sobre a linha produtiva, determinando $\mathrm{e}$ restringindo as tarefas individuais e, definindo detalhadamente toda a jornada de trabalho. A qualificação do trabalhador e o conhecimento

\footnotetext{
${ }^{28}$ WALKER, Shaun. Tobacco giant Philip Morris sold cigarettes made using child labour. The Independent. Reino Unido, 15 jul. 2010. Disponível em: <http://www.independent.co.uk/news/world/asia/tobaccogiant-philip-morris-sold-cigarettes-made-using-childlabour-2026759.html>. Acesso em: 13 jul. 2014.

29 INTERNATIONAL LABOUR RIGHTS FORUM. Cocoa Campaign. Disponível em: <http://www.laborrights.org/industries/cocoa>. Acesso em: 13 jul. 2013.

30 GORZ, André. Misérias do presente, riqueza do possível. Tradução Ana Montoia. São Paulo: Annablume, 2004. p. 38.
}

generalizado sobre o processo produtivo eram indesejáveis. À época, entendia-se que o meio de impedir o controle do processo de trabalho pelos trabalhadores era a dissociação entre concepção e execução.

O resultado dessa dissociação foi a desqualificação do trabalhador, restrito a reduzida quantidade de tarefas simplificadas e rotineiras, de alta grau de especialização e, o controle do trabalho pelas empresas, por meio de inovações técnicas e organizacionais, que permitiam a desvalorização dos empregados, com o achatamento de seus salários, e a máxima produção de lucros para os donos dos meios de produção. ${ }^{31}$

O acirramento da concorrência e a insuficiência do mercado consumidor, entretanto, puseram fim ao crescimento do Fordismo, deixando às empresas poucas alternativas, sendo a mais importante delas renovar de forma acelerada o seu leque produtivo, provocando a rápida desatualização de seus produtos. Para isso, as empresas precisariam envidar intensos esforços em matéria de inovação e desenvolver a capacidade de produzir em séries cada vez mais curtas e a custos unitários cada vez mais baixos ${ }^{32}$. Nesse momento, passou-se a experimentar o Pós-Fordismo.

A empresa pós-fordista substitui o paradigma da organização pela rede de fluxos interconectados, "coordenados em seus núcleos por coletivos auto-organizados sem que nenhum deles constitua propriamente um centro". ${ }^{33}$ No lugar de uma produção organizada de forma centrada, em que os operários atuavam estritamente de acordo com o padrão imposto para o alcance do resultado final, sem compreender a contribuição de seu trabalho no

\footnotetext{
${ }^{31}$ BRAVERMAN, H. Trabalho e capital monopolista. Rio de Janeiro: Zahar, 1981. p. 82-83.

32 GORZ, André. Misérias do presente, riqueza do possível. Tradução Ana Montoia. São Paulo: Annablume, 2004. p. 37.

${ }^{33}$ Ibidem, p. 41.
} 
todo, tem-se um sistema em que os empregados se auto-organizam de forma descentrada para contribuírem para o resultado final, levando a uma cooperação produtiva.

A referida transição ao invés de significar a almejada libertação dos trabalhadores do trabalho e no trabalho, o que se imaginaria uma vez que se põe fim ao mecanicismo das atividades dos empregados que passam a atuar de forma mais reflexiva e intelectual, representa, ao contrário, "a sujeição máxima dos trabalhadores, obrigando-os a cumprir por si mesmos a função patronal [...], fazendo-os erigir o interesse da empresa acima inclusive de sua saúde e de sua vida". ${ }^{34}$ Isso porque o caráter emancipador do Pós-Fordismo só existiu nos raros casos em que a "implicação de si" exigida dos trabalhadores pode ser negociada por sindicatos fortes e atuantes. ${ }^{35}$

A nova forma de sujeição proposta pelo Pós-Fordismo, aproveitando-se da manutenção do desemprego estrutural e todos os problemas sociais que já assolavam o modelo anterior que frutificou em uma sociedade em decomposição, se baseia no conhecido "patriotismo de empresa", solução apresentada pelo capital para a sujeição dos operários que nela encontram identidade e interação social.

Nas palavras de André Gorz:

A firma apresenta-lhe o tipo de conforto que oferecem as ordens monásticas, as seitas, as comunidades de trabalho: ela pede que renuncie a tudo - a qualquer outra forma de pertencimento, a seus interesses e até mesmo a sua vida pessoal, a sua personalidade - para entregar-se de corpo e alma à empresa, e em troca, lhe dará uma identidade, um pertencimento, uma personalidade, um trabalho do qual pode orgulhar-se; torna-se membro de uma "grande família". O laço que estabelece com a empresa e com o coletivo de trabalho da empresa passa a ser o único elo social, absorve toda a sua energia, mobiliza toda a pessoa

34 GORZ, André. Misérias do presente, riqueza do possível. Tradução Ana Montoia. São Paulo: Annablume, 2004. p. 41.

35 Ibidem, p. 43. do trabalhador e traz o risco, para ele, da perda total de si quando, pela excelência indefinidamente crescente de seu desempenho, deixasse de merecer a confiança da firma, a consideração de seus colegas. ${ }^{36}$

O Pós-Fordismo representa, em verdade, um retrocesso. No Fordismo, a relação entre empresas e trabalhadores era conflituosa e dependente de contínua negociação. Os trabalhadores não pertenciam à empresa e lhe deviam exclusivamente uma prestação de horas definida em contrato de trabalho. Como sujeitos, os empregados tinham sentimento de pertença exclusivamente a si mesmo e à sua classe, inserindo-se em uma dinâmica conflitual em que se buscava uma limitação crescente da exploração do capital. É essa dinâmica que é bloqueada pelo Pós-Fordismo.

Tendo por princípio que o pertencimento do assalariado à empresa deve prevalecer sobre seu pertencimento à sociedade e à sua classe, o Pós-Fordismo enfraquece o direito do trabalho e o poder do sindicato e das negociações coletivas. O direito da empresa sobre seus empregados é mais valorizado do que os direitos que a cidadania social e econômica confere aos trabalhadores. ${ }^{37}$

Em resumo, o Pós-Fordismo pede aos trabalhadores que reflitam, que prevejam, que discutam o que fazem, sendo sujeitos autônomos de produção, mas que limitem sua autonomia às balizas pré-determinadas pela empresa, pois introjeta em suas mentes a ideia de que fazem parte de pequena "elite" intocada pelo desemprego, levando-os a verdadeira sujeição.

Cabe dizer, ainda, que além das consequências já apontadas do Pós-Fordismo para o mundo do trabalho, relacionadas à sujeição social e cultural dos trabalhadores às firmas, o novo sistema mantém em seu bojo um grande prejuízo antes pouco representativo no contexto do Fordismo: a terceirização.

\footnotetext{
${ }^{36}$ Ibidem, p. 47-48.

${ }^{37}$ Ibidem, p. 49.
} 
A firma matriz externaliza as tarefas especializadas e de produção taylorista a empresas que são dela dependentes, impondolhes baixas de preço contínuas e fazendo-as suportar as flutuações de demanda. Esse contexto penoso faz com que as subcontratadas estabeleçam a seus empregados condições precárias de trabalho, para que viabilizem sua própria existência. ${ }^{38}$

Assim, o Pós-Fordismo divide a mão-deobra em duas categorias: um núcleo de assalariados pertencentes à matriz sujeitados socialmente à empresa e sem qualquer capacidade de resistência e, uma massa de trabalhadores periféricos, submetidos a condições precárias de trabalho.

\section{CONSEQUÊNCIAS DA TRANSIÇÃO: A NOVA MARGINALIZAÇÃO}

A transição descrita no item anterior representa mais do que uma simples reindustrialização. Corresponde, em verdade, a uma transformação na sociedade que cria novas necessidades e consequentes novas atividades, a maioria delas precárias e pertencentes ao setor terciário.

A nova divisão do trabalho é composta por trabalhadores especializados e com maior nível de conhecimento, que exercem cargos de alta atividade cognitiva, por trabalhadores especializados em atividades técnicas e por trabalhadores com pouca especialização que ocupam os postos de trabalho mais degradantes. ${ }^{39}$ Como explicam Luc Boltanski e Éve Chiapello:

Ela [a estrutura social] também levou à dualização dos assalariados $e$ à fragmentação do mercado de trabalho, com a formação de dois mercados: por um lado, uma mão de obra estável, qualificada,

38 GORZ, André. Misérias do presente, riqueza do possível. Tradução Ana Montoia. São Paulo: Annablume, 2004. p. 459

${ }^{39}$ Ibidem, p. 383. beneficiada por um nível salarial relativamente elevado e na maioria das vezes sindicalizada nas grandes empresas; por outro, uma mão de obra instável, pouco qualificada, mal remunerada $e$ pouco protegida nas pequenas empresas prestadoras de serviços subsidiários. Além disso, a concentração em certas populações de desvantagens prolongadas, engendradas por essa precarização, acelerou os processos de exclusão. ${ }^{40}$

A tendência atual, entretanto, é que a "elite empresarial" seja cada vez mais restrita e insuficiente para a "desproletarização" da classe operária. Há, portanto, o aumento do número de trabalhadores assalariados fora da produção material, flexibilizados, precarizados e atípicos.

As novas figuras do mercado de trabalho paulatinamente se configuram em "formas ocultas de trabalho assalariado, subordinado, precarizado, não garantido, de trabalho autônomo de última geração, que mascara a dura realidade da eliminação do ciclo produtivo". ${ }^{41}$

As preocupações com o desenvolvimento dos trabalhadores na gestão empresarial dizem respeito exclusivamente àqueles que têm possibilidade de acesso a empregos mais bem remunerados e mais protegidos. Sua relevância nos processos produtivos e sua presença contínua na organização incentivam os empregados a preocupar-se com seu futuro na empresa e até fora dela, oferecendo-lhes aprimoramento ou aumentando sua polivalência. Mas esses esforços ocultam uma realidade infeliz para os que são relegados à margem, aqueles que atuam temporariamente nos locais de trabalho ou nas horas em que os outros não estão presentes, ou então aqueles que estão sob a responsabilidade de uma subcontratada que não tem, necessariamente, condições de oferecer as mesmas oportunidades que a empresa principal oferece. "Os discursos e os esforços que giram

${ }^{40}$ BOLTANSKI, Luc; CHIAPELLO, Ève. O novo espírito do capitalismo. Tradução Ivone C. Benedetti. São Paulo: Martins Fontes, 2009. p. 253.

${ }^{41}$ VASAPOLLO, Luciano. A precariedade como elemento estratégico determinante do capital. Pesquisa \& Debate, São Paulo, v. 16, n. 2(28), p. 368-386, 2005. p. 385. 
em torno da empregabilidade mascaram, portanto, ao mesmo tempo, a exclusão de fato dos inempregáveis." ${ }^{42} \mathrm{O}$ redesenho do perfil da empresa e a exteriorização de certas funções mostrou-se como uma ocasião para relegar os empregos não qualificados a um status menos vantajoso, atribuindo sua responsabilidade a terceiristas ou enquadrando-os em contratos precários. $^{43}$

Com o aumento do desemprego e a intensificação da concorrência no mercado de trabalho, os trabalhadores do sistema de subcontratação, frequentemente isolados, já não dispõem dos recursos suficientes para pressionar os empregadores ou resistir a eles, estando em total situação de submissão. A legião de subcontratados se vê excluída do status frequentemente mais vantajoso previsto pela convenção coletiva ou pelo acordo da empresa principal, que também encontra na terceirização a oportunidade para eximir-se em parte de sua responsabilidade em casos de acidentes do trabalho ou doenças profissionais. ${ }^{44}$

Ao mesmo tempo, as dificuldades do mercado de emprego alimentam um processo de regressão social também na "elite empresarial". A novidade que se deve ressaltar é que as convenções coletivas, outrora consideradas capazes de melhorar as condições dos assalariados, agora passam a degradá-las. Elas transgridem limites até então aceitos e afastamse do entendimento de que a estagnação é permitida, mas nunca o retrocesso.

Ao estimular o recurso à negociação, especialmente em nível de empresa, a lei deu aos empregadores a oportunidade de validar suas próprias reivindicações, de tal modo que as negociações clássicas em vista de melhoria de direitos e vantagens dos assalariados em relação aos requisitos mínimos legais foram pouco a pouco substituídas por negociações que buscavam acordos "toma lá dá cá", nos quais a relação de forças, desfavorável aos assalariados, redundava na esperança da manutenção do emprego por parte deles, porém em vantagens tangíveis para o empregador, tais como revisão das modalidades de aumento ou de determinação dos salários ou mudanças na jornada de trabalho. $\mathrm{O}$ aumento da participação do "direito negociado" em relação ao "direito legislado", portanto, acentuou a disparidade entre os trabalhadores em termos de direitos (disparidade que já existia, mas não com essa dimensão, devido à técnica do limite de efetivos). Agora se registram, com mais frequência do que antes, variações entre setores, entre empresas e até mesmo entre grupos de assalariados dentro da mesma empresa. ${ }^{45}$

O Pós-Fordismo instaurou uma nova marginalização social, em que o trabalhador precarizado é difundido e não se vê como um sujeito coletivo capaz de exigir direitos e dignidade $^{46}$ e $\mathrm{o}$ trabalhador das empresas principais se vê de tal forma tão dependente de seu empregador que, ainda que se identifique com uma única categoria, não é capaz de sustentar pleitos trabalhistas em face do mesmo.

Enfim, seja por meio da sujeição social, seja por meio da terceirização, alicerçado no desemprego estrutural, o Pós-Fordismo dá ao capitalismo um novo suporte à precariedade, como brilhantemente sintetiza Luciano Vasapollo:

Um novo ciclo do capitalismo, um novo modelo está se formando junto com o fim da mão-de-obra, com o desemprego estrutural, com o desemprego invisível, o trabalho ilegal e mal remunerado, a precariedade e a flexibilização, que cria ao mesmo tempo os amortizadores do conflito social, através das altas remunerações dos operários especializados, e desenvolve uma aristocracia assalariada que participa e se converte em sujeito co-gestor. $^{47}$

\section{CONCLUSÃO}

\footnotetext{
${ }^{42}$ VASAPOLLO, Luciano. A precariedade como elemento estratégico determinante do capital. Pesquisa \& Debate, São Paulo, v. 16, n. 2(28), p. 368-386, 2005. p. 257-258.

${ }^{43}$ Ibidem, p. 262.

${ }^{44}$ Ibidem, p. 270.
}

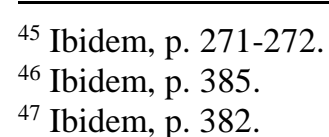


Dentre os diversos fatores que impactaram o antigo primado do trabalho e emprego, levando à paulatina desvalorização da força de trabalho e degradação dos trabalhadores, a globalização, o surgimento das transnacionais e o processo de reestruturação empresarial são aqueles que mais contribuíram para a precarização do trabalho.

A globalização, ao facilitar a mobilidade do capital e a migração de empresas para os países com salários mais baixos, nos quais o custo do trabalho é reduzido, favoreceu a extensão da concorrência entre os trabalhadores em escala mundial. Viabilizando o surgimento, a expansão e o domínio das empresas transnacionais "flexíveis", que definem sua localização de acordo com a aceitação (ou não) de condições deploráveis de trabalho, a globalização maximizou a insegurança dos empregados e os tornou mais dóceis à exploração.

Com o fim do Estado do Bem-Estar Social e com a intensificação do processo globalizante, a competitividade e a insegurança no trabalho mostraram-se incompatíveis com o pleno emprego e diversas garantias sociais. O avanço das políticas neoliberais e o fim das barreiras territoriais resultaram em um processo profundo de desarticulação da classe trabalhadora, institucionalizando-se o modelo de regulação do "precariado", alicerçado na ruptura do emprego estável, e na ascensão das formas atípicas de emprego.

Ao mesmo tempo, o novo modelo de produção que passou a imperar sobre todos os países, o Pós-Fordismo, por meio da sujeição social do núcleo de assalariados das grandes empresas, delas plenamente dependentes e sem qualquer capacidade de resistência e, por meio da criação de uma massa de trabalhadores periféricos, terceirizados, submetidos a condições precárias de trabalho, deu ao capitalismo um novo suporte à precariedade.

Dessa forma, estando-se diante de uma globalização que não tende a retroceder e de um modelo produtivo que há anos se mostra o mais efetivo economicamente, pequenas são as esperanças de reversão da precariedade que assola o mundo do trabalho. É preciso, para o alcance do pleno emprego, uma luta política, que encoraje as vítimas da exploração da insegurança a agir em conjunto contra os promotores da precarização, mobilizando-se em escala global. Faz-se necessária a construção de uma identidade

coletiva.

\section{REFERÊNCIAS}

ALVES, G. Dimensões da Reestruturação Produtiva: ensaios de Sociologia do Trabalho. Londrina: Praxis, 2007.

ANTUNES, Ricardo. Os modos de ser da informalidade: rumo a uma nova era da precarização estrutural do trabalho? Serviço Social e Sociedade, São Paulo, n. 107, julho/setembro, 2011.

BOLTANSKI, Luc, CHIAPELlO, Ève. O novo espírito do capitalismo. Tradução Ivone C. Benedetti. São Paulo: Martins Fontes, 2009.

BOURDIEU, Pierre. A precariedade está hoje por toda parte. In: BORDIEU, Pierre. Contrafogos: táticas para enfrentar a invasão neoliberal. Rio de Janeiro: Jorge Zahar, 1998, p. 72-77.

BRAVERMAN, H. Trabalho e capital monopolista. Rio de Janeiro: Zahar, 1981. 
CASTEL, Robert. As transformações da questão social. In: CASTEL, R; WANDERLEY L. E. W.; BELFIORE-WANDERLEY, M. Desigualdade e a questão social. São Paulo: EDUC, 2004.

. El ascenso de las incertidumbres. Trabajo, protecciones, estatuto del individuo. Buenos Aires: Fondo de Cultura Económica, 2010.

Seuil, 2009.

La montée des incertitudes. Travail, protections, statut de l'individu. Paris: Éditions du . Les Métamorphoses de la question sociale. Paris: Gallimard, 1995.

. Metamorfoses da questão social. Petrópolis: Vozes, 1998.

DELGADO, Maurício Godinho. Capitalismo, Trabalho e emprego: entre o paradigma da destruição e os caminhos de reconstrução. São Paulo: LTr, 2006.

GONÇALVES, Antônio Fabrício de Matos. Flexibilização trabalhista. Belo Horizonte: Mandamentos Editora, 2004.

GORZ, André. Misérias do presente, riqueza do possível. Tradução Ana Montoia. São Paulo: Annablume, 2004.

FONSECA, Francisco. O Consenso Forjado - a grande imprensa e a formação da agenda ultraliberal no Brasil. São Paulo: HUCITEC, 2005.

FUDGE, Judy; TUCKER, Eric; VOSKO, Leah F. The legal concept of employment: marginalizing workers. Report for the Law Comission of Canada, set. 2002.

HUMAN RIGHTS WATCH. Bottom of the Ladder: Exploitation and Abuse of Girl Domestic Workers in Guinea. Nova York, 2007. Disponível em: $<$ http://www.hrw.org/sites/default/files/reports/guinea0607webwcover.pdf $>$. Acesso em: 25 set. 2013.

Lonely Servitude: Child Domestic Labor in Morocco. Nova York. 2012.

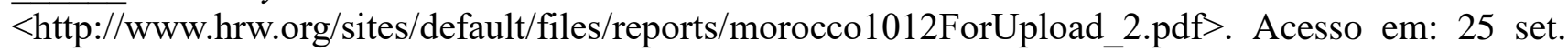
2013.

INTERNATIONAL LABOUR RIGHTS FORUM. Cocoa Campaign. Disponível em: $<$ http://www.laborrights.org/industries/cocoa>. Acesso em: 13 jul. 2013.

KINLEY, D; TADAKI, J. From talk to walk: The emergence of human rights responsibilities for corporations at international law. Virginia Journal of International Law, v. 44, n. 4, p. 931-1023.

LESSA, R. R. Z.; REIS, D. M. . SUBMISSÃO DAS CORPORAÇÕES A SANÇÕES INTERNACIONAIS E MEIOS NÃO ESTATAIS DE REPARAÇÃO: Possíveis soluções à ineficácia social do Direito ao Trabalho Decente. Anuário Brasileiro de Direito Internacional, v. 2, p. 89-113, 2015.

MARTINS ZANITELLI, Leandro. Corporações e Direitos humanos: O Debate entre Voluntaristas e Obrigacionistas e o Efeito Solapador das Sanções. Sur - Revista Internacional de Direitos humanos, 
v. $8, \quad$ n. 15, dez. 2011. Semestral. Disponível em: $<$ http://www.surjournal.org/conteudos/pdf/15/02.pdf > . Acesso em: 11 fev. 2014.

MILMO, Cahal. The hard labour behind soft drinks. The Independent. Reino Unido, 24 fev. 2012. $<$ http://www.independent.co.uk/life-style/food-and-drink/features/the-hard-labour-behind-softdrinks-7440046.html>. Acesso em: 13 jul. 2014.

OIT. World of Work Report 2013 - Repairing the economic and social fabric. $<$ http://www.oit.org.br/sites/default/files/topic/gender/doc/relatoriocompletowow13_1037.pdf>. Acesso em: 03 out. 2013.

VASAPOLLO, Luciano. A precariedade como elemento estratégico determinante do capital. Pesquisa \& Debate, São Paulo, v. 16, n. 2(28), p. 368-386, 2005.

WALKER, Shaun. Tobacco giant Philip Morris sold cigarettes made using child labour. The Independent. Reino Unido, 15 jul. 2010. Disponível em: $<$ http://www.independent.co.uk/news/world/asia/tobacco-giant-philip-morris-sold-cigarettes-madeusing-child-labour-2026759.html>.

Recebido em: 07/03/2016

Aceito em: 02/08/2016 

globalizado 